\title{
Multispectral and multiangle measurements of acoustic seabed backscatter acquired with a tilted calibrated echosounder
}

\author{
Ridha Fezzani, ${ }^{1, a)}$ Laurent Berger, ${ }^{1}$ Naig le Bouffant, ${ }^{1}$ Luciano Fonseca, ${ }^{2}$ and Xavier Lurton ${ }^{1}$ \\ ${ }^{1}$ Institut Français de Recherche pour l'Exploitation de la Mer, Underwater Acoustics Laboratory, CS 10070, \\ 29280 Plouzané, France \\ ${ }^{2}$ Department of Electronic Engineering, Universidade de Brasilia at Gama, Brasilia, Brazil
}

\begin{abstract}
:
A multispectral and multiangle analysis of seabed backscatter intensity has been conducted using data from a calibrated single-beam echosounder (SBES) with five frequency channels deployed over four homogeneous areas with different sediment types in the Bay of Brest (France). The SBES transducers were tilted at incidence angles from $0^{\circ}$ to $70^{\circ}$ to record the seafloor backscatter angular response at discrete frequencies ranging from 35 to $450 \mathrm{kHz}$. The recorded backscatter levels were analyzed for their angular dependence (average backscatter strength versus frequency and angle) as well as for their sample statistical distribution. The angle and frequency dependence of the seafloor backscatter obtained using a calibrated SBES can potentially be used to calibrate multibeam systems, and it can also help in elucidating the physical processes of backscatter controlled by the interaction between the acoustic wave characteristics and the sediment properties. Backscatter measurements for each area showed a consistent frequency dependence with little variation between the four sediment types.

(C) 2021 Acoustical Society of America. https://doi.org/10.1121/10.0005428
\end{abstract}

(Received 26 January 2021; revised 11 May 2021; accepted 1 June 2021; published online 23 June 2021)

[Editor: Stephen Paul Robinson]

Pages: $4503-4515$

\section{INTRODUCTION}

The acoustic backscatter (BS) angular response (AR), which depicts the way the mean BS strength changes with incidence angle when acquired at large scales over homogeneous areas of seabed reflectivity, is acknowledged to be an effective proxy for remote seabed type identification as the sediment AR is intrinsically linked to geoacoustic and geometric properties of the seafloor sediments (Lamarche et al., 2011; Lurton and Lamarche, 2015). Nevertheless, the AR is also dependent on the acoustic frequency; this is caused by the seabed roughness (scaled by the signal wavelength) and by the different levels of sediment volume scattering due to a deeper signal penetration at lower frequencies. Thus, this frequency dependence can potentially be used for a better discrimination among sediments. Recently, thanks to technological advances in wideband sonar echosounders, multifrequency measurement of seabed BS has become an operational option for scientific surveys, and several studies of remote sediment classification have addressed the potential of multifrequency analysis of the seafloor BS with these systems (Brown et al., 2019; Feldens et al., 2018; Gaida et al., 2018; Clarke, 2015; Janowski et al., 2018) showing its benefits but also highlighting the complex interaction between acoustics signals and the seabed response at multiple wavelengths. These studies contribute to a better understanding of the relationship between sediment properties and their acoustic response-a necessary step for the

a)Electronic mail: Ridha.Fezzani@ifremer.fr analysis of the BS strength over a wide range of frequencies. The multibeam echosounders (MBESs) available today for coastal and continental-shelf applications fall into two wide classes: the $170-450 \mathrm{kHz}$ range [e.g., R2Sonic (Austin, TX) 2026, Teledyne RESON (Slangerup, Denmark) Seabat T50, Norbit (Trondheim, Norway) WBMS, and Kongsberg Maritime (Kongsberg, Norway) EM2040] and the $45-120 \mathrm{kHz}$ range (e.g., Kongsberg Maritime EM712, Simrad ME70). Normally, MBESs are narrowband systems that transmit continuous wave $(\mathrm{CW})$ signal pulses at one single center frequency or from a set of adjacent frequencies. Hence, to cover a frequency range of at least one octave or more [which is the minimum requirement for a significant multifrequency analysis (Clarke, 2015)], a combination of at least two MBES systems transmitting alternatively is needed. Such a multifrequency MBES survey is actually impractical, as it requires multiple acquisitions of the same lines with different systems and possibly different vessels. Recent technological advances have made MBES systems able to simultaneously collect BS data at different frequencies (although this is usually obtained by alternating pings at various frequencies rather than by a strict synchronicity), e.g., the R2Sonic $2026(170-450 \mathrm{kHz}$ with optional 90 and $100 \mathrm{kHz})$, the Norbit WBMS $(200-700 \mathrm{kHz})$, the Teledyne Seabat T50 (190-420 kHz), and the Kongsberg Maritime EM2040 (200-700 kHz). Unfortunately, even these recent MBES systems are still not calibrated for absolute BS strength measurements, making it difficult to compare data from different systems and even data from the same MBES but at different frequencies. On the other hand, the recently 
released Simrad EK80 single-beam echosounder (SBES) can be fully calibrated using the classical method of the frequency-dependent sphere target (Demer et al., 2015). Additionally, this SBES can cover a wide frequency band $(10-500 \mathrm{kHz})$ when equipped with several transducers pinging simultaneously (Demer et al., 2017). Hence, it can be used as a reference sensor for measuring the absolute BS levels needed for further cross-calibration of MBESs (Eleftherakis et al., 2018) as a function of both angle and frequency. To address the need for these cross-calibration procedures, we present here a multispectral analysis of seabed BS intensity using data from an EK80 SBES equipped with five transducers and operated over four homogeneous areas covered with different sediment types in the Bay of Brest (France). The SBES transducers were tilted at various incidence angles from $0^{\circ}$ to $70^{\circ}$ to record seafloor ARs at different frequencies ranging from 35 to $450 \mathrm{kHz}$. To present a complete methodology, the calibration procedure for the reference SBES is described and discussed as well as the survey configuration, the statistics of scattered signals, and an analysis of the frequency dependence of the BS AR.

\section{BACKGROUND AND PREVIOUS WORK}

While a large number of papers have been published about in situ measurement results of seafloor BS, only a few of them address systematic measurements with simultaneous variations in frequency and angle. A non-exhaustive but representative list is given below with brief descriptions; their main results are synthesized in Table I, with an emphasis on the frequency dependence. Note that they are quite varied with regard to the acquisition conditions and acoustic systems and may not be directly comparable due to their dispersion in angle and frequency ranges as well as their inhomogeneity in description and characterization of the seafloor properties.

The pioneering paper of McKinney and Anderson (1964) presents a synthesis of BS measurements acquired on 16 shallow-water locations over a wide variety of seafloor types (from rock to mud), with frequency ranging from 12.5 to $290 \mathrm{kHz}$ and incidence angles mainly from $30^{\circ}$ to $85^{\circ}$, using several tilted transducers with beam apertures of $5^{\circ}-10^{\circ}$ calibrated over a reference sphere and $0.5 \mathrm{~ms} \mathrm{CW}$ signals. Despite a strong dispersion in their results, they observed and synthesized the main BS features recognized ever since (average BS values increasing from mud to sand, gravel, and rock; dependence on both grain size and interface roughness; level globally decreasing from steep to grazing angles). With regard to frequency dependence, they found that average BS strength increased approximately as $f^{1.6}$ for several sand sediments, but they could not find clear frequency trends, neither in fine sediments nor in rocky areas. Jackson et al. (1986a) report measurement results over six shallow-water areas with seafloor types from silt to gravel. The frequencies ranged from 20 to $85 \mathrm{kHz}$, generated by three tilted transducers with quite a large aperture

TABLE I. Summary of results from multifrequency seafloor BS studies.

\begin{tabular}{|c|c|c|c|c|}
\hline Sediment type & Reference & Frequency range $(\mathrm{kHz})$ & Incident angle (deg) & BS variation (dB/octave) \\
\hline Rock & McKinney and Anderson (1964) & $12.5-290$ & $30-85$ & 0 \\
\hline Rock/boulders & Cutter and Demer (2014) & $18-200$ & $0-20$ & 1.4 \\
\hline Rock/boulders/steep & & & & 2.3 \\
\hline Sand/cobble/boulders & & & & 0.9 \\
\hline Sand/cobble & & & & 1.3 and 2.6 \\
\hline Gravel & Weber and Ward (2015) & $170-250$ & 45 & -2 to -2.4 \\
\hline Fine gravel & Jackson et al. (1986a) & $20-45$ & $40-80$ & $1.5\left(70^{\circ}\right)$ \\
\hline Sand/gravel/steep & Cutter and Demer (2014) & $18-200$ & $0-20$ & 3.2 \\
\hline Sand/gravel/flat & & & & -0.75 \\
\hline Coarse sand/shells & Stanic et al. (1989) & $20-180$ & $60-85$ & -0.75 \\
\hline Sand (averaged) & McKinney and Anderson (1964) & $12.5-290$ & $30-85$ & 4.8 \\
\hline \multirow[t]{2}{*}{ Sand } & Williams et al. (2009) & $10-150$ & $40-70$ & $3\left(70^{\circ}\right)$ \\
\hline & & $150-500$ & & $6\left(70^{\circ}\right)$ \\
\hline Sand ripples & Weber and Ward (2015) & $170-250$ & 45 & -1 to -2.2 \\
\hline Sand waves & & & & $0-1$ \\
\hline \multirow[t]{2}{*}{ Medium sand } & Jackson et al. (1986a) & $20-48$ & $45-80$ & $2\left(70^{\circ}\right)$ \\
\hline & Greenlaw et al. (2004) & $265-1850$ & $70-81$ & 5 \\
\hline \multirow[t]{2}{*}{ Medium-fine sand } & Wendelboe (2018) & $180-330$ & $0-70$ & $0.7-1.1$ \\
\hline & & $330-400$ & & $4.0-4.4$ \\
\hline Fine sand & Jackson et al. (1986a) & $20-48$ & $0-80$ & $1.6\left(70^{\circ}\right)$ \\
\hline Very fine sand & & 20-80 & & 0.8 \\
\hline Fine sediments & McKinney and Anderson (1964) & $12.5-290$ & $30-85$ & 0 \\
\hline Silty sand & Jackson et al. (1986a) & $20-85$ & $0-85$ & 1.4 \\
\hline \multirow[t]{2}{*}{ Sand and mud } & Williams et al. (2009) & $30-150$ & $40-70$ & $0\left(60^{\circ}\right)$ \\
\hline & & $150-500$ & & $6\left(60^{\circ}\right)$ \\
\hline Sandy silt & Jackson et al. (1986a) & $20-85$ & $20-75$ & $-0.2\left(70^{\circ}\right)$ \\
\hline
\end{tabular}


(around $10^{\circ}-20^{\circ}$ horizontal and $40^{\circ}$ vertical) installed on a towed platform. The angle dependence was obtained mainly from split-beam measurements and covered up to $0^{\circ}-85^{\circ}$, depending on the sites. The frequency analysis conducted at incidence $70^{\circ}$ showed no strong frequency dependence, with slopes ranging from -0.2 to $2.0 \mathrm{~dB}$ /octave. Stanic et al. (1989) conducted BS measurements from a tower deployed on an area with coarse sand topped by hashed shells; frequencies ranged from 20 to $180 \mathrm{kHz}$, generated by a parametric source with a $3^{\circ}$ beam tilted between $60^{\circ}$ and $85^{\circ}$. The receiver was a discrete hydrophone array; little information is given on the calibration of the complete system. The angle dependence followed Lambert's law at all frequencies. Although not really conclusive, a slight negative frequency dependence of the Lambert offset was observed over the frequency range. The work by Greenlaw et al. (2004) is more dedicated to higher frequencies $(265 \mathrm{kHz}$ to $1.85 \mathrm{MHz})$. The data were recorded using a multifrequency echosounder over a sand seafloor at grazing angles. The results show the Lambert parameter first increasing with frequency and then decreasing at $1 \mathrm{MHz}$ and beyond. The paper by Williams et al. (2009) presents results from two sandy sites with significantly different seafloor characteristics and response; the interpretation was that one area was dominated by the sand interface roughness and the other one by a significant contribution from soft sediment volume. The frequencies ranged from 10 to $2000 \mathrm{kHz}$ and from 30 to $500 \mathrm{kHz}$, respectively, and the incidence angles ranged from $40^{\circ}$ to $70^{\circ}$. At frequencies below $150 \mathrm{kHz}$, the roughness-dominated $\mathrm{BS}$ increased by $3 \mathrm{~dB} /$ octave, while the volume-dominated $\mathrm{BS}$ showed no frequency dependence. At $150-500 \mathrm{kHz}$, a similar frequency dependence (around $6 \mathrm{~dB} /$ octave) was found for both sites. Using a vertical split-beam calibrated SBES with several transducers, Cutter and Demer (2014) studied the angle and frequency dependence of the BS strength at discrete frequencies $18-38-70-120-200 \mathrm{kHz}$ for near-nadir incidence angles (typically up to $20^{\circ}$ ) over different seafloor types characterized by frequent mixes of geological features and significant topography features. In this steep angle sector, they found a frequency dependence varying between -0.7 and $3.1 \mathrm{~dB} /$ octave according to the local seafloor type. Weber and Ward (2015) also used a calibrated wideband SBES covering the band $170-250 \mathrm{kHz}$, tilted at $45^{\circ}$ over six locations with various coastal sediments; their results show a weak frequency dependence for all seafloor types, with a small decrease with increasing frequency except for one area of medium sand. Finally, Wendelboe (2018) presented extensive measurements of acoustic BS with frequencies ranging from 190 to $400 \mathrm{kHz}$ and incidence angles from $0^{\circ}$ to $70^{\circ}$ in bins of $5^{\circ}$ using an in-tank calibrated multibeam echosounder; he found an increase in the seafloor scattering strength with the increasing frequency at all incidence angles, with a change to a steeper spectral slope occurring between 300 and $400 \mathrm{kHz}$.

It is difficult to synthesize and unify these various results into clear trends; their dispersion illustrates the complexity of the bottom scattering mechanisms, which are still not well understood, despite several decades of effort since the very first experimental work on the topic (Urick, 1954). Moreover, part of these discrepancies may also be due to challenges in the experimental process, such as problems in the absolute calibration of the acoustic system and difficulties in recording consistent measurements over wide ranges of frequencies and angles. Historically, much of this previous work is mainly concerned with oblique to grazing angles; recent articles tend to focus on steeper angles, presumably due to the increasing importance of seabedmapping applications using MBESs (Lurton and Lamarche, 2015). Studying the angular dependence of BS has long been a prevalent topic; all the experimental results concur in observing a strong angular variation around the vertical, followed by a stable intermediate area at oblique angles and a final decrease at grazing angles. The interpretation of this angle dependence has been addressed in a variety of approaches, from the simplest, Lambert's law, to sophisticated physical models of composite roughness and porous media (Jackson and Richardson, 2007). In this respect, we conducted systematic measurements over the $0^{\circ}-75^{\circ}$ sector, and we used for our data analysis the generic seafloor acoustic backscatter (GSAB) model (Lamarche et al., 2011) simply expressed by a small number of parameters interpretable as basic physical concepts of interface roughness and impedance contrast. The frequency dependence has been relatively less studied in the past and is hence less well understood. Most previous results tend to show fundamentally a BS increase with increasing frequency. However, the increase rate depends on the angular sector and on the seafloor type; in a minority of cases, a decrease with increasing frequency has been reported. Still insufficiently understood but prone to be more widely documented, thanks to the generalization of multifrequency echosounders, this intricate frequency dependence can be taken as a potential advantage for further work in remote seafloor-type classification. To explore this dimension as usefully as possible and to take advantage of the current echosounder technology, we propose here observations at frequencies spanning over one decade by third-of-octave steps.

\section{MATERIALS AND METHODS}

\section{A. Experimental site characterization}

The experimental data for measuring acoustic BS strength over multiple frequencies and over a wide range of angles were recorded during a survey in April 2018 in the Bay of Brest, France. The four surveyed areas are shown in Fig. 1. They were selected from previous mapping surveys, which showed them to be homogeneous and flat. To assist in the interpretation of the results, grab samples and videos were taken in each area just after the end of the acoustical data acquisition. The main results are summarized in Fig. 2.

The Carré Renard site comprises a flat area, 19-m deep and covered with coarse sand and gravel mixed with broken shells. It is currently used by the French Navy Hydrographic Service (SHOM) as a bathymetric reference area to assess 


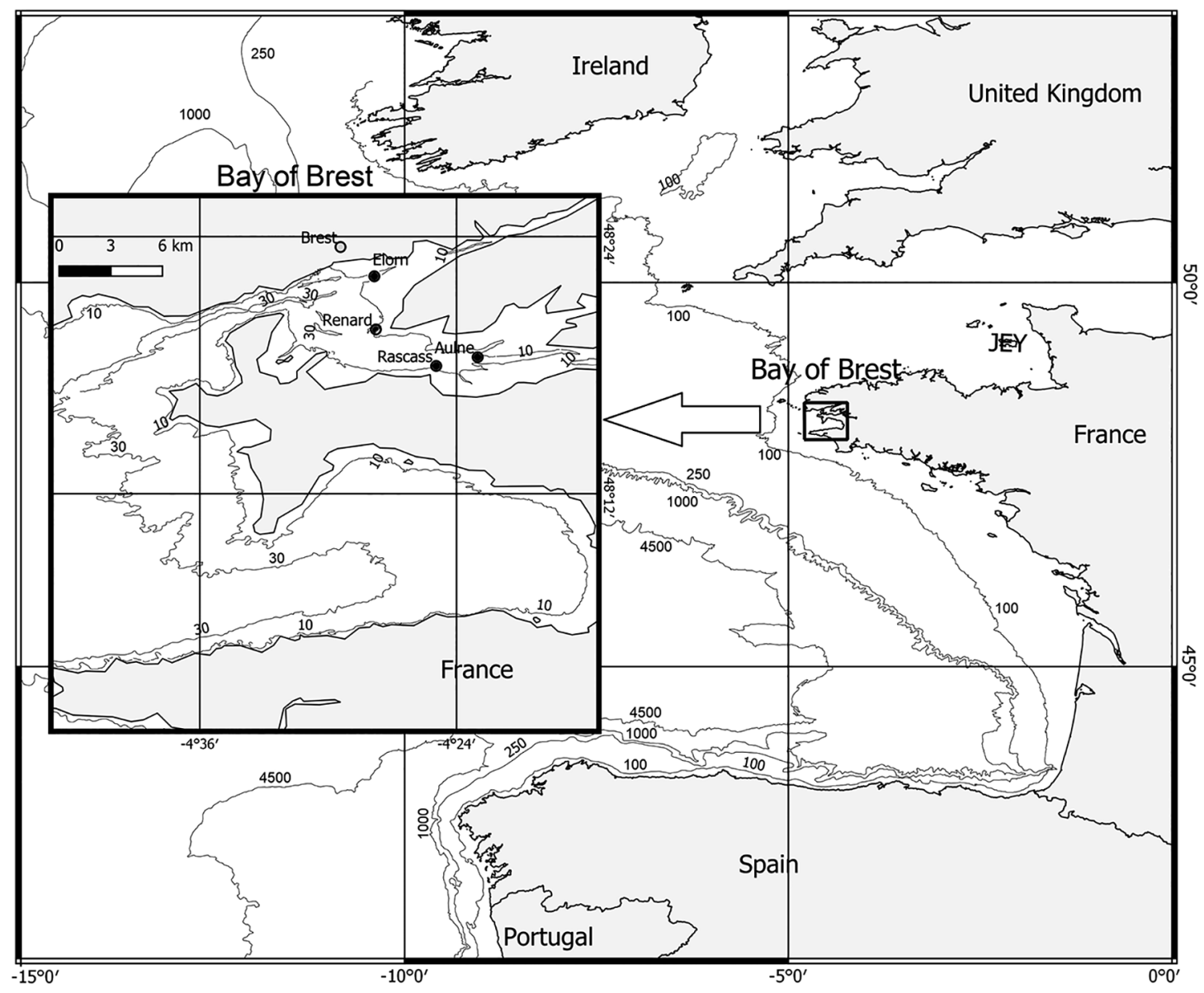

FIG. 1. Location of the four experimental sites in the Bay of Brest.

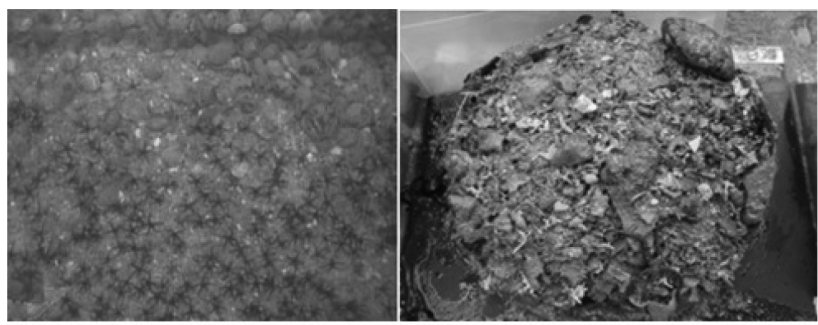

(A)

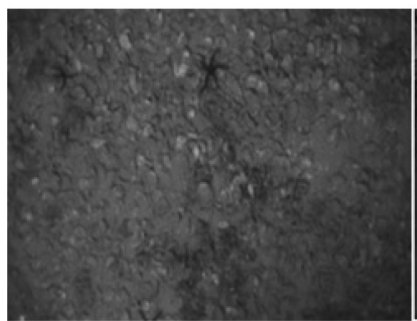

(C)

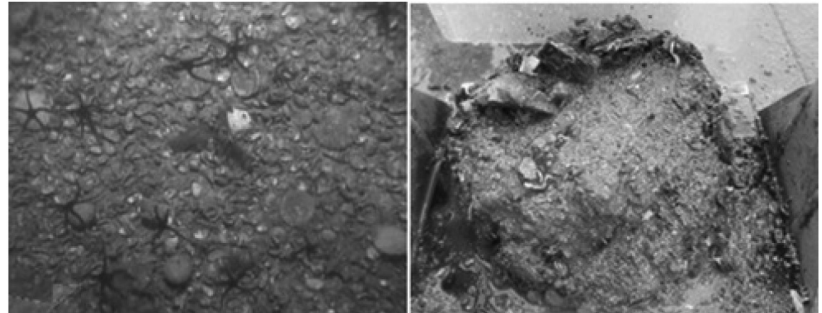

(B)

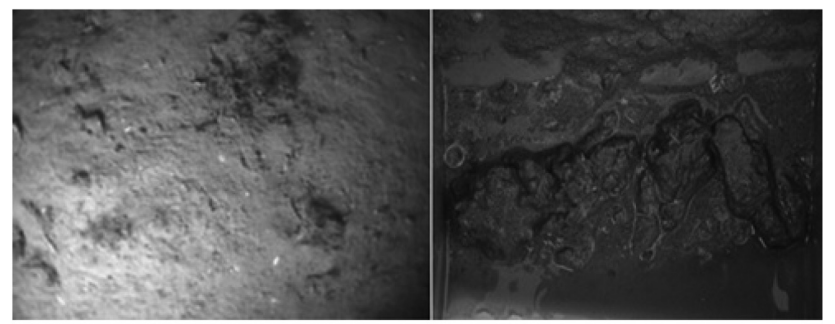

(D)

FIG. 2. Seafloor sediment photos, including Renard [gravelly sand with coarse elements (A)], Rascass [gravelly mud with shells (B)], Aulne [silty sand with shells (C)], and Elorn [mud (D)]. For each site, a pair of images is shown from videos and grab samples. Each seafloor image encompasses an area of approximately $1 \mathrm{~m}^{2}$. 
the hydrographic quality of shallow-water sonar systems (Roche et al., 2018). The main observed biological feature in this area is the presence of a dense colony of brittle stars. The average sediment composition is homogeneous over the entire area, resulting in a homogeneous BS response (Eleftherakis et al., 2018; Roche et al., 2018). The sediment cover at the Rascass site is basically composed of gravelly mud, while the Aulne site is composed of silty sand. Both Rascass and Aulne are about 23-m deep, and both areas are covered with broken shells. The Elorn river estuary site is covered with a muddy sediment, at a mean depth of about $26 \mathrm{~m}$. A sedimentology analysis of the Bay of Brest is presented in detail in Gregoire et al. (2016).

\section{B. Survey configuration}

\section{EK80 description and calibration}

Five Simrad EK80 wideband transceivers (Demer et al., 2017) have been used for this experiment, with five Simrad split-beam transducers, at nominal frequencies of 38, 70, 120, 200, and $333 \mathrm{kHz}$. They were controlled by an EK80 processing unit with a specially installed version of the acquisition software (version 1.12), allowing for the generation and transmission of $\mathrm{CW}$ signals as well as frequencymodulated (FM) signals in a user-specified frequency band (the standard version of the EK80 software allows only for the use of $\mathrm{CW}$ signals at each transducer nominal frequency). This special software version made it possible to apply the standard processing of seafloor BS with CW signals as described in Eleftherakis et al. (2018) while exploring the complete frequency band between 35 and $450 \mathrm{kHz}$ at regular steps (thirds of octaves). Complex-value data of each quadrant of the split-beam transducers were stored in raw format after initial filtering and decimation by the EK80 software (Demer et al., 2017). The five EK80 modules were first calibrated in the Institut Français de Recherche pour l'Exploitation de la Mer (IFREMER) tank facility in Brest. The calibration was then checked at quayside on RV Thalia (Eleftherakis et al., 2018). The SBES was calibrated according to the procedure described in Demer et al. (2015), using two tungsten-carbide spheres with a $6 \%$ cobalt binder, with respective diameters of 25 and $38.1 \mathrm{~mm}$, following the calibration functionality provided in the EK80 software. Since the broadband frequency response for a given calibration sphere contains nulls at specific frequencies, depending on the sphere diameter, the use of two spheres with different diameters made it possible to have a flat response of the target strength all over the explored frequency range. During in-tank calibration, the EK80 transducers were mounted and steered using a pan-and-tilt dedicated device. The spheres were suspended with a thin monofilament line $(0.2 \mathrm{~mm})$ at a fixed position, minimizing interaction with the sphere echoes. The EK80 transducers were then calibrated at each CW frequency and also in FM mode to check consistency between calibration results at the various frequencies. The in-tank calibration curves used in this study are given in Fig. 3. They cover the frequency range from 29 to $450 \mathrm{kHz}$

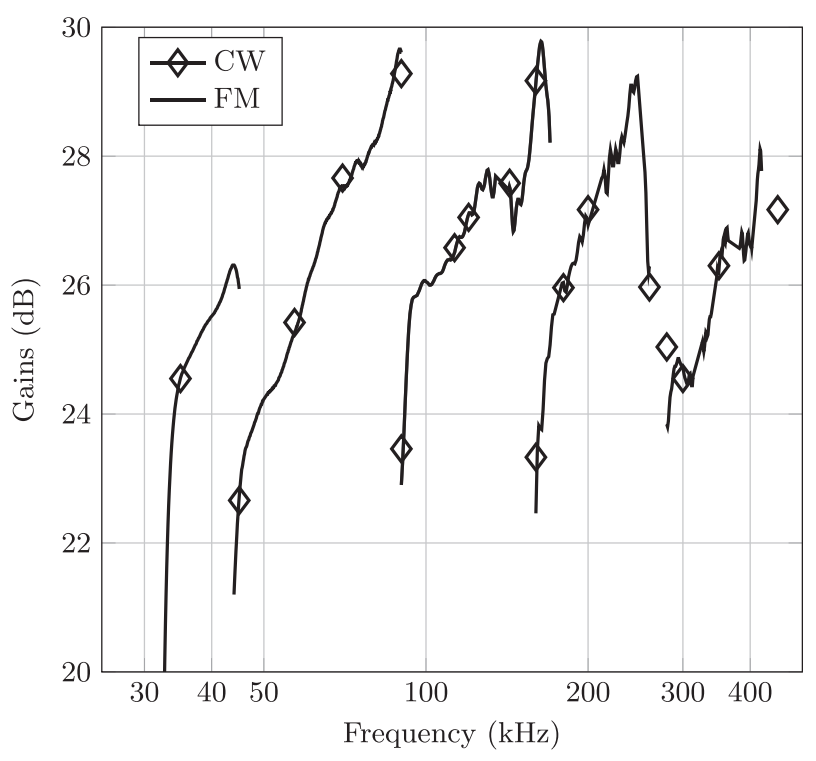

FIG. 3. Calibration gains for five EK80 transducers and transceivers in CW and FM modes, measured in tank.

acquired by the five transducers using FM mode as well as discrete $\mathrm{CW}$ frequencies. A residual difference (less than $1 \mathrm{~dB}$ ) between CW and FM gains is still observed at the 260- and $450-\mathrm{kHz}$ frequencies that are close to operational bandwidth limits of the ES333-7C transducer. Due to their respective spectra, $\mathrm{CW}$ and $\mathrm{FM}$ pulses integrate the transducer frequency response over different bandwidths; this is likely to result in the slightly different gain values observed for $\mathrm{CW}$ and FM in these dynamic parts of the transducer response. We used the standard deviation of the gain value, calculated for all sphere BS measurements, to estimate the calibration uncertainty of the EK80. The maximum standard deviation for the gain value in-tank measurements was found to be equal to $0.15 \mathrm{~dB}$, with an average value of $0.08 \mathrm{~dB}$ across the whole frequency band.

\section{Backscatter measurements}

To optimize the survey duration, up to three EK80 transducers were simultaneously installed on a vertical pole fixed on the hull side of the coastal survey ship RV Thalia (Fig. 4). This arrangement made it possible for the transducers to ping simultaneously at different frequencies. The transducers fixed at the pole tip were tilted using a pan-andtilt device, remotely controlled from the ship; the transducers could be steered in the horizontal and vertical planes at any required angle, with an accuracy on the order of $1^{\circ}$. The transducer depth was approximately $3.5 \mathrm{~m}$. The pulse length was set to $256 \mu$ s for a sufficient signal-to-noise ratio, except for the $333-\mathrm{kHz}$ transducer transmitting $1024 \mu \mathrm{s}$ pulses. The frequencies and pulse lengths used during the survey of the four sites are summarized in Table II.

For the Renard and Rascass sites, the BS observations were collected for frequencies from 35 to $450 \mathrm{kHz}$, by steps of one-third of an octave, with some frequencies slightly adjusted to avoid the target resonances at calibration. This 


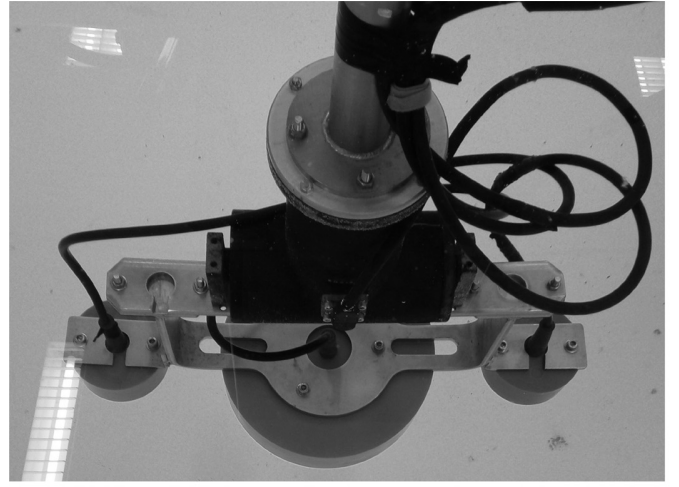

(a)

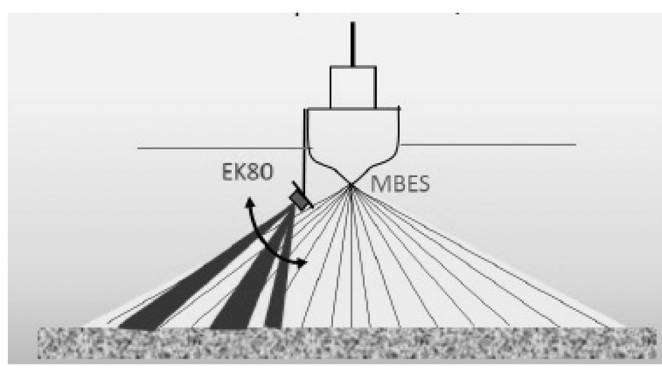

(b)

FIG. 4. EK80 measurement configuration. (a) The pan-and-tilt system fixed at the tip of the pole with the three EK80 transducers attached. (b) Schematic representation of a SBES measurement configuration. The tilted SBES provides a reference AR of the seafloor.

frequency range $(35-450 \mathrm{kHz})$ covers most frequencies commonly used for MBES surveys, except for deep-water areas. To shorten the acquisition time, only two or three transducers were used to survey the Aulne and Elorn sites. Two frequencies (90 and $160 \mathrm{kHz}$ ) were common to different transducers, so they were used as control frequencies for the transducer calibration and to assess the repeatability of the survey.

The survey strategy was to run each survey line back and forth with the transducers steered at a different angle for each passage. The tilt angles varied from $-3^{\circ}$ to $70^{\circ}$ (from vertical) by steps of $3^{\circ}$ or $5^{\circ}$. For each angle, at least 30 pings were recorded to ensure a robust estimation of the average BS AR. The EK80 data processing is detailed in Eleftherakis et al. (2018); the main difference introduced here is a correction of the SBES aperture to account for the ratio between the nominal frequency of the transducer and the actually operated frequency. The final bottom scattering strength per incident angle is the average, over all the pings, of the BS values computed for each ping according to

$$
B S=S_{v}+10 \log _{10}\left(r^{2} \frac{c T_{\text {eff }}}{2} \psi\left(\frac{f_{n}}{f}\right)^{2}\right)-10 \log _{10} S-D F,
$$

where $S_{v}$ is the measured volume BS strength (in $\mathrm{dB}$ ) provided by the SBES (Demer et al., 2017); $r$ is the sonar-target range $(\mathrm{m}) ; \psi$ is the nominal equivalent aperture of the source/receiver system; $T_{\text {eff }}$ is the effective pulse length; $f_{n}$ and $f$ are the nominal frequency of the transducer and the current frequency, respectively; $S$ is the insonified area $\left(\mathrm{m}^{2}\right)$; and $D F$ is the beam directivity function $(\mathrm{dB})$, depending on along and athwart angles. The terms $S$ and $D F$ also depend on the beam width, which in turn depends on the ratio of the nominal frequency to the current one. Note that the average is computed using the natural values of BS [not the $\mathrm{dB}$ values as expressed in Eq. (1)].

To extract the BS AR from the data recorded by the tilted SBES, we first take the mean value of all samples binned within $\pm 1^{\circ}$ around the bottom detection instant. Then we average these values for all pings to get one mean BS value per nominal incident angle. The last step consists in fitting the GSAB model (Lamarche et al., 2011) to the angle-dependent averaged BS. The GSAB model represents the BS AR as a combination of a Gaussian law for specular angles and Lambert-like law for grazing angles. The model is given by

$$
B S(\theta)=10 \log _{10}\left[A \exp \left(-\theta^{2} / 2 B^{2}\right)+C \cos ^{D}(\theta)\right],
$$

where

- A quantifies the specular maximum amplitude. In the tangent plane (or facets) classical theory (Brekhovskikh et al., 1991), it is related to the coherent reflection

TABLE II. Values of frequencies and pulse lengths used during the surveys of the four sites.

\begin{tabular}{lcc}
\hline \hline Site & Transducer model and frequency range $(\mathrm{kHz})$ & Survey frequencies $(\mathrm{kHz})$ \\
\hline Renard & ES38-10 (34-45) & 35 \\
Renard and Rascass & ES70-7C (45-90) & $45-57-70-90$ \\
& ES120-7C (90-170) & $90-113-143-160$ \\
& ES200-7C (160-260) & $160-180-200-226-260$ \\
& ES333-7C (280-450) & $280-300-360-450$ \\
Aulne & ES120-7C (90-170) & $90-113-143-160$ \\
& ES333-7C (280-450) & $280-300-360-450$ \\
Elorn & ES120-7C (90-170) & $90-143-160$ \\
& ES200-7C (160-260) & 1024 \\
& ES333-7C (280-450) & $256-180-226-260$ \\
\hline
\end{tabular}


coefficient at the water seabed interface and is therefore high for smooth sediment interfaces (at the acoustic wavelength's scale) and for strong water sediment impedance contrasts.

- $B$ quantifies the angular extent of the specular regime. In the tangent plane model, $B^{2}$ is the facet slope variance and is therefore an interface roughness descriptor.

- $C$ quantifies the average BS level at oblique incidence. It is similar to the offset of the classical method with Lambert's law describing BS at intermediate angles for rough interfaces and includes the contribution of the volume inhomogeneity BS. $C$ increases with seafloor roughness and impedance and heterogeneities present inside the sediment volume.

- $D$ is the BS angular decrement commanding the falloff at grazing angles. It is high for soft and smooth sediment interfaces.

We apply a nonlinear least-square optimization algorithm to estimate the best fit. Figure 5 shows an example of a dataset averaging and fitting process: after accounting for the athwart phase and for roll angle of each sample used to estimate the final BS AR, it is possible to plot a continuous angular histogram of the BS strength, similarly to the results obtained from MBES measurement [Fig. 5(a)]; the final output shows an estimation of the absolute BS AR for the current frequency and for the sediment configuration [Fig. 5(b)]. The quality of the fitting operation is given by the residual magnitude computed by the optimization algorithm; this was found to be typically around $0.5 \mathrm{~dB}$ for most cases studied here.

\section{RESULTS}

\section{A. Angular and frequency dependence of amplitude statistics}

The BS levels, measured at a given insonified area, may vary significantly, depending on the acoustic frequency, on the incidence angle of the acoustic wavefront, on the

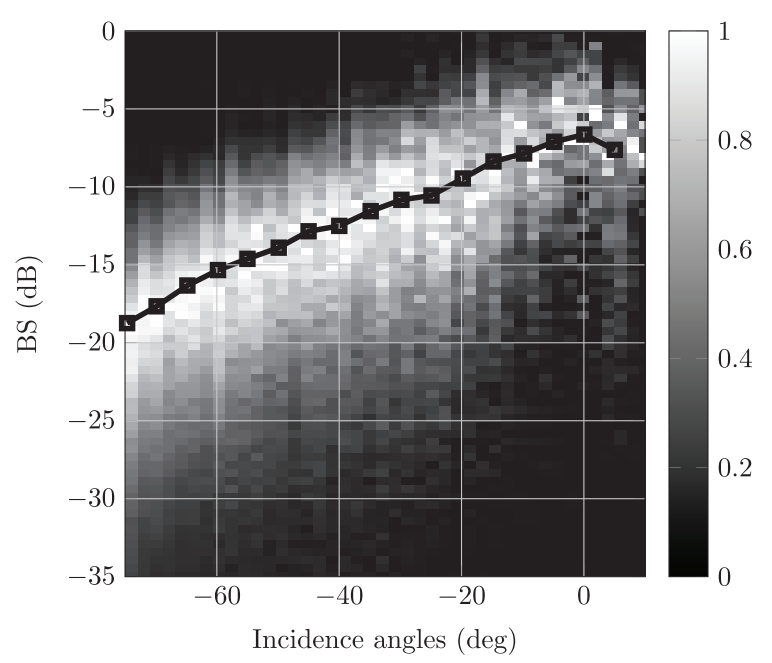

(a) number of averaged samples, and on the way the samples are averaged. Thus, before constructing the final BS AR, it is useful to study these variations by analyzing the statistics of the BS samples. While Rayleigh's law provides a good approximation in many cases (Jackson and Richardson, 2007), several non-Rayleigh distributions have also been proposed for seafloor BS intensity analysis, such as Kdistribution, Weibull, gamma, log-normal, mixed Rayleigh, etc. (Amiri-Simkooei et al., 2009; Fonseca et al., 2021; Jackson and Richardson, 2007; Le Chenadec et al., 2007; Lyons and Abraham, 1999; Penrose et al., 2008). Note that in the present study, we do not focus on the best fit of the BS intensity statistics but on the angular dependence of the seafloor BS fluctuation statistics. These variations were addressed in Fonseca et al. (2021). The Weibull probability density function (PDF) shown below is strictly defined for positive values of the shape parameter $\beta$ and the scale parameter $\alpha$. This distribution is highly flexible. Depending on the shape parameter $\beta$, it can cover other PDFs, ranging from the exponential distribution $(\beta=1)$ to the Rayleigh distribution $(\beta=2)$ and up to normal (Gaussian) distribution $(\beta>3.5)$,

$$
f(x, \alpha, \beta)= \begin{cases}\frac{\beta}{\alpha}\left(\frac{x}{\alpha}\right)^{\beta-1} e^{-\left(\frac{y}{\alpha}\right)^{\beta}} & x \geq 0, \\ 0 & x<0 .\end{cases}
$$

Using this Weibull PDF, a systematic analysis has been applied to the dataset considered here. For each one of the four areas, the recorded data are processed at the various frequencies, using all the pings available for each case. All samples within a $1^{\circ}$ bin around the angle associated with the bottom detection time stamp are used to adjust a Weibull distribution. The adjustment is done using the maximum likelihood estimation method. Figure 6 depicts the result of this processing for some frequencies as a plot of the values

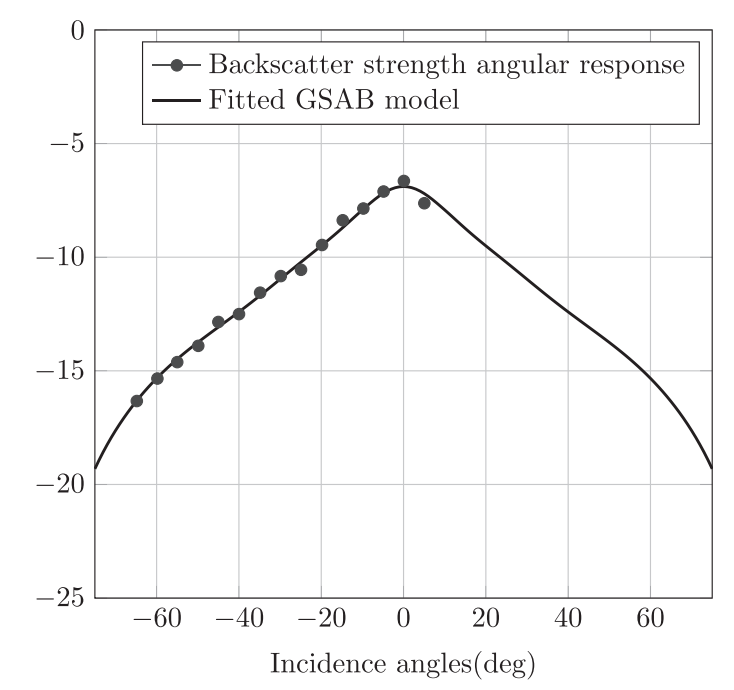

(b)

FIG. 5. Example of angular BS estimation from EK80 data (Renard at $143 \mathrm{kHz}$ ). (a) Normalized histogram of BS for each incident angle with superimposed mean values. (b) GSAB model fitted to EK 80 averaged measurements; the RMS difference between the mean values and the fitted model is here equal to $0.4 \mathrm{~dB}$. 
Gravelly sand with coarse elements (Renard)

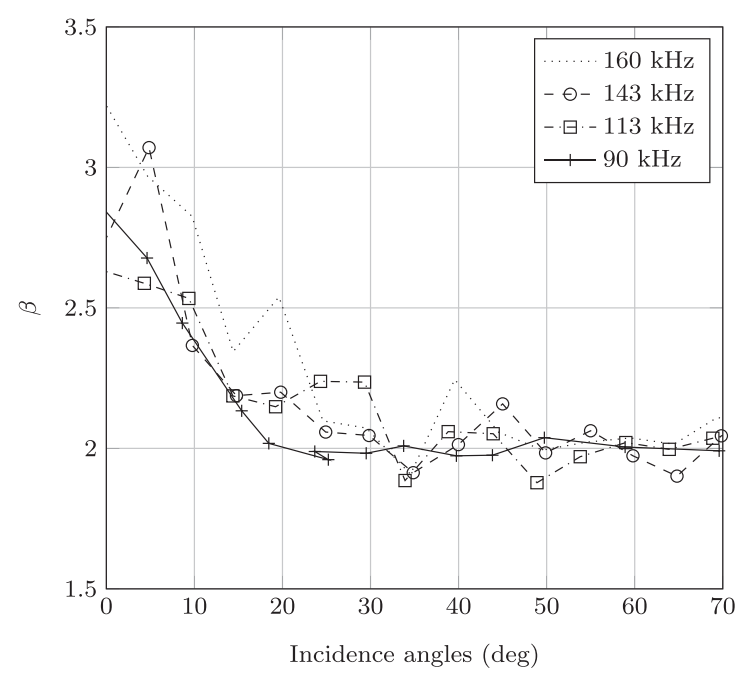

Silty sand with shells (Aulne)

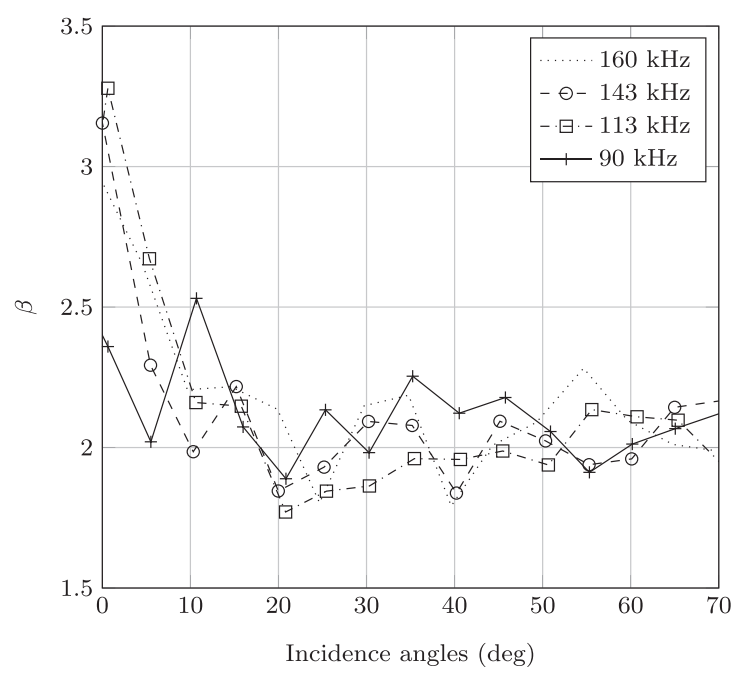

Gravelly mud with shells (Rascass)

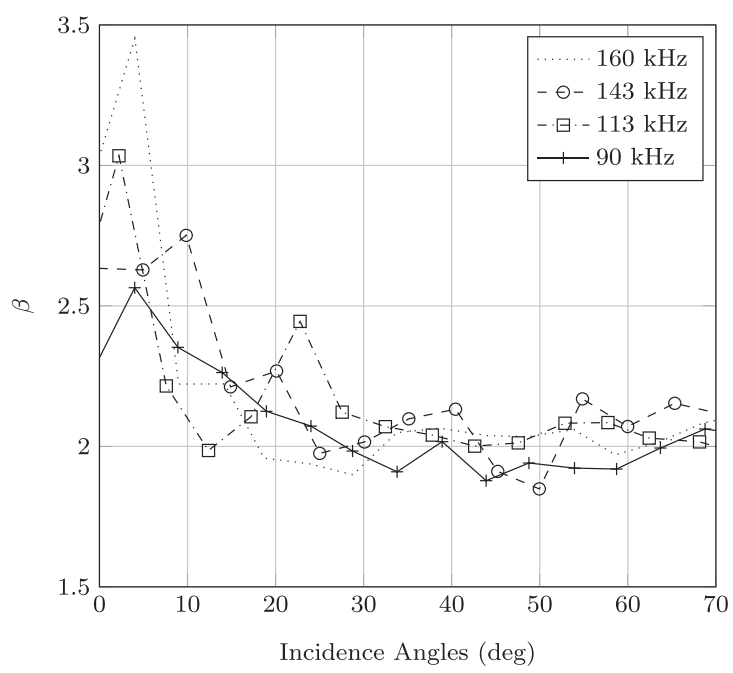

Mud (Elorn)

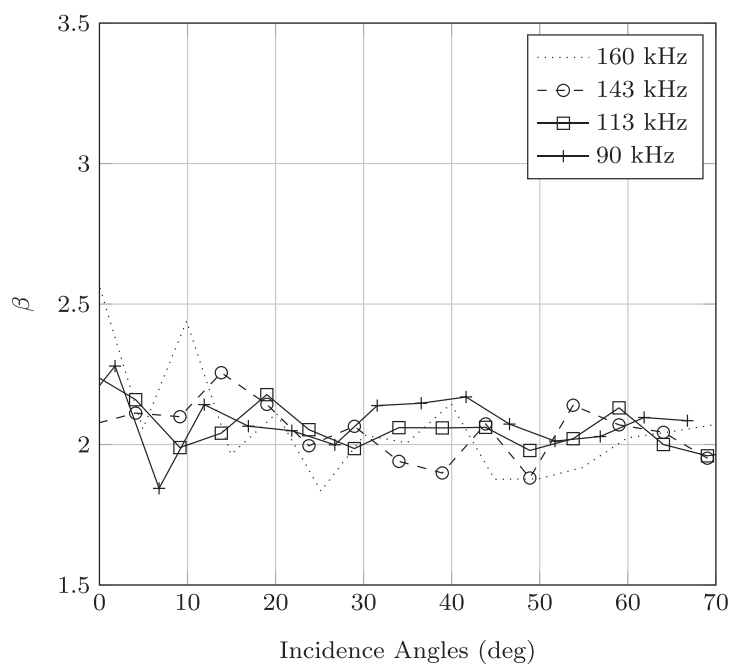

FIG. 6. Angle dependence of the $\beta$ parameter from BS data recorded at various frequencies on the four seafloor areas (see main text). The BS values are binned in $1^{\circ}$ bins around the discrete incidence angles (from $0^{\circ}$ to $70^{\circ}$ by $5^{\circ}$ steps) and fitted to a Weibull distribution. The $\beta$ parameter of the Weibull law is plotted here as a function of the incidence angle for the four areas.

of the $\beta$ parameter versus the incidence angle for the four survey sites. It shows that $\beta$ remains around 2.0 (characteristic of a Rayleigh distribution) for all angles beyond $20^{\circ}$, without noticeable difference between the seafloor types. As the angles go steeper and finally vertical, the adjusted $\beta$ coefficient shows a positive trend; at the vertical, $\beta$ reaches values between 2.2 and 3.4 with little observable difference between the four areas. For the Elorn data, the $\beta$ values remain very close to 2.0 independently of the incidence angle, except at the vertical, and for other sites, one observes a monotonic increase in the $\beta$ values for decreasing incident angle, reaching the highest values around 3.0. The behavior of the Elorn site can be explained based on the local nature of the seafloor, which is composed of soft mud. The low acoustic impedance of this soft sediment allows for a significant penetration of signals inside the sediment, especially around the vertical, resulting in a Rayleigh regime caused by the mixed contributions of multiple embedded scatterers.
Conversely, for other sites, a number of strong scatterers are present at the water-bottom interface, possibly causing instable peak values at steep angles and leading to higher $\beta$ values. The available number of acoustic samples for the statistical fitting also plays an important role on the $\beta$ estimation; too small a number causes a trend toward higher values of $\beta$ (Fonseca et al., 2021). This is especially prone to happen at steep incidences, where a small number of usable samples are available; this trend is, however, lessened for soft sediments, which allow for signal penetration, such as here in the Elorn area. In this study, to avoid the consequences of using a small number of samples, a minimum number of only 30 pings were acquired in Aulne and Rascass and about 90 for Elorn and Renard. Possibly, the observed increase in $\beta$ values at steep incidence can be explained by a conjunction of both the sediment characteristics and the number of available samples used for the statistical analysis. 


\section{B. Frequency dependence measurements}

Figure 7 presents the BS AR curves (actually, their GSAB-fitted version) recorded at all frequencies over the four test sites. The GSAB model proved to fit very satisfactorily to the various datasets, with RMS residual differences typically $0.5-1 \mathrm{~dB}$. Besides the classical variation with angle (specular peak spreading until $10^{\circ}-20^{\circ}$, level plateau at oblique angles, and falloff typically beyond $60^{\circ}$ ), this clearly confirms the strong dependence of the mean BS level on both the seafloor substrate and the acoustic frequency. Note that only the Renard and Rascass sites were measured at the lowest frequencies $(35-46-57 \mathrm{kHz})$, causing a very significant spreading toward the lower BS values. In all cases, the specular peak near-normal incidence changes in width and height, according to frequency. These results are in accordance with the physical considerations discussed in Jackson and Richardson (2007), predicting the specular peak to be most pronounced for the lowest frequencies. For the Elorn area, the roll-off with incidence angle associated with a steep specular peak is also in accordance with the expected behavior of soft sediments. The shape variation of these curves will be addressed in Sec. $\mathrm{V}$, including the frequency dependence of the vertical-to-oblique BS difference and the mean BS strength at $45^{\circ}$. Finally, values of frequency dependence coefficients will be extracted and compared with previous works at similar frequency ranges and incidence angles.

\section{DISCUSSION}

To illustrate the frequency dependence of the BS AR for each survey site, the difference between the BS values at near-normal incidence $\left(B S_{N} ; \theta=0^{\circ}\right)$ and at oblique incidence $\left(B S_{O} ; \theta=45^{\circ}\right)$ is plotted in Fig. 8. For the Renard and Aulne sites, the $B S_{N}-B S_{O}$ difference (respectively, 6-9 and 4-6 dB) shows no significant trend with the changing frequency except for frequencies below $100 \mathrm{kHz}$ at the Renard site, where it clearly increases to $10-13 \mathrm{~dB}$. This flat response can be explained by a rough seafloor material, as ground truthing showed the ubiquitous presence of shells in these two areas. On the other hand, the high values of the specular peak and the high average level suggest a strong impedance contrast that was also confirmed by video and ground truthing. For the Elorn muddy area, the $B S_{N}-B S_{O}$ difference decreases linearly with increasing frequency until $300 \mathrm{kHz}$ and then becomes stable for higher frequencies at a level of about $12 \mathrm{~dB}$. For the Rascass site, the $B S_{N}-B S_{O}$ difference decreases with the increasing frequency from high values (around $15 \mathrm{~dB}$ ) at lowest frequencies down to
Gravelly sand with coarse elements (Renard)

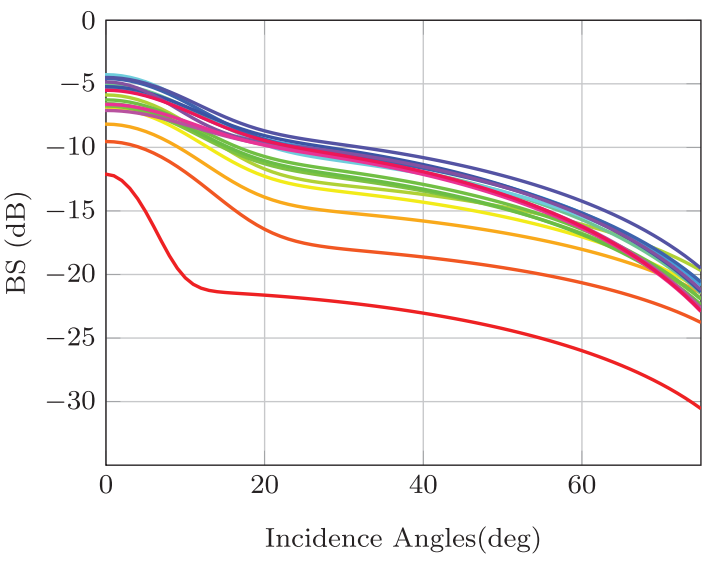

Silty sand with shells (Aulne)

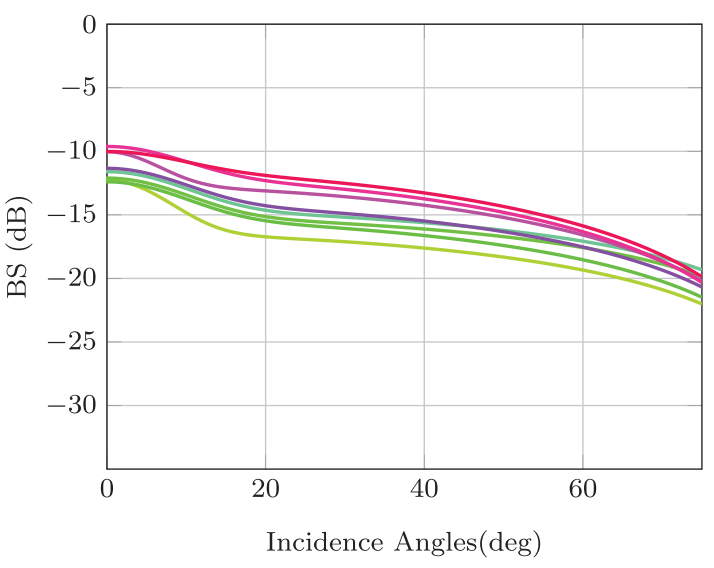

Gravelly mud with shells (Rascass)

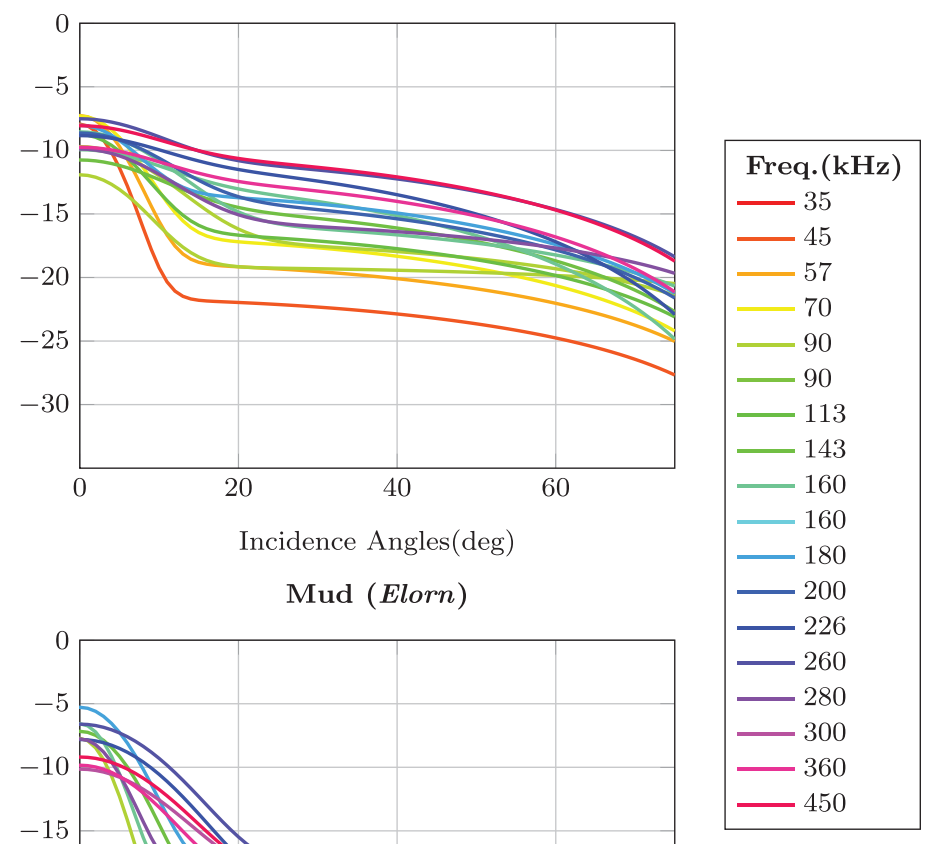

FIG. 7. GSAB model fitted to measured BS values for all frequencies on the four experimental sites. The average root mean square (rms) difference between the averaged experimental values and the fitted model (see Fig. 5) shows a typical magnitude of $0.5-1 \mathrm{~dB}$. 


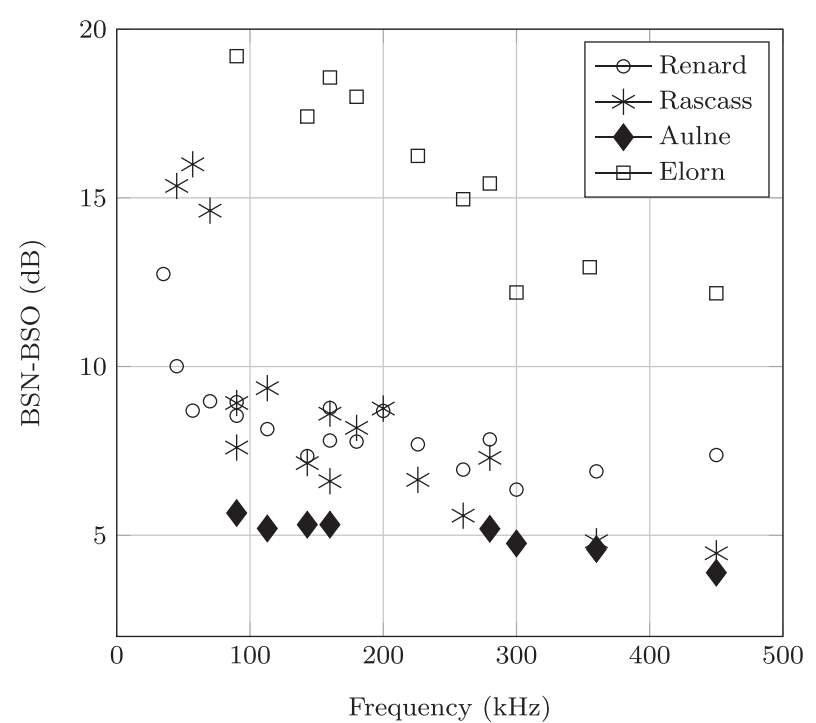

FIG. 8. Frequency dependence of $B S_{N}-B S_{O}$ (contrast between BS values at $0^{\circ}$ and $45^{\circ}$ ).

values comparable to Aulne above $300 \mathrm{kHz}$. To summarize, this $B S_{N}-B S_{O}$ difference could be significantly related to the sediment type, based on its magnitude and its frequency dependence; however, the available data are still insufficient today to interpret these observed variations, especially for mixed sediments, suggesting that other parameters and descriptors should be also considered.

Figure 9 summarizes the BS strength at $45^{\circ}$ versus the acquisition frequency for all sites. This average $B S_{45^{\circ}}$ value is very similar to the offset parameter of the classical Lambert's law applied in similar studies (Williams et al., 2009) and determined by dividing the BS cross section by $\cos ^{2} \theta$ (where $\theta$ is the angle of incidence). In the GSAB model used to fit our experimental results (Lamarche et al., 2011), the Lambert-like dominant regime at oblique angles

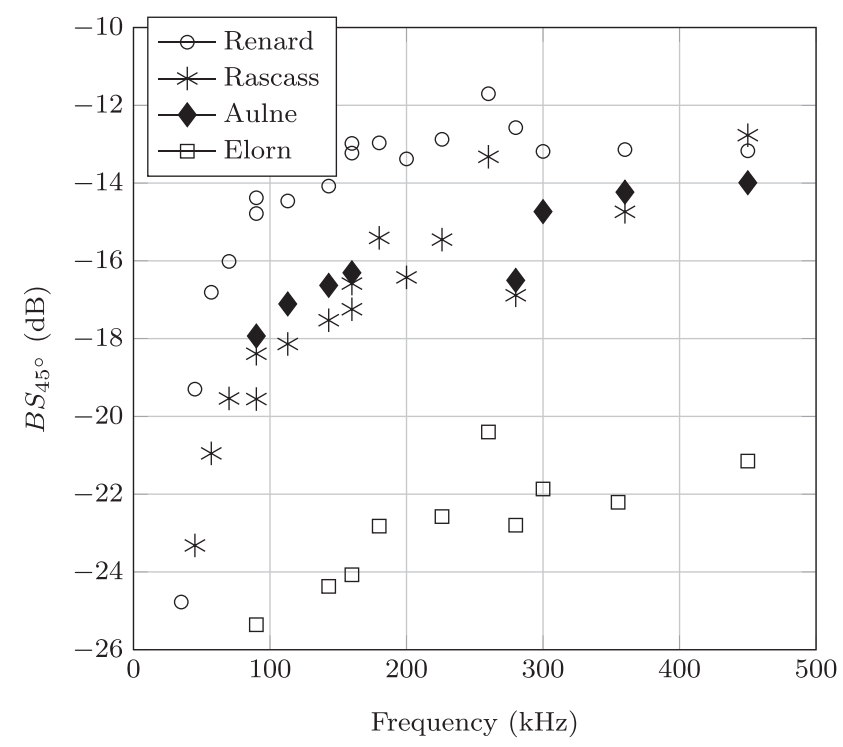

FIG. 9. Comparison of bottom BS strength measured at $\theta=45^{\circ}$ at the four sites. is accounted for by a power-cosine term $\left(\cos ^{D} \theta\right)$. This allows for a better fit of various angular behaviors, hence avoiding the a priori hypothesis of a squared cosine dependence while introducing one extra parameter (i.e., the power exponent $D$ ). To simplify the analysis, we chose here to use the $B S_{45^{\circ}}$ values. We found this mean oblique BS strength increasing with frequency for all sites. This variation remains consistent in the analyzed frequency range, except at frequencies 180 and $260 \mathrm{kHz}$, which showed deviations of about $1-3 \mathrm{~dB}$ at all sites. This inconsistency is probably caused by uncertainties in the applied gain for these frequencies, which proved difficult to calibrate, as they are located in the falloff edges of the frequency response curves of the $200-$ and $333-\mathrm{kHz}$ transducers (see Fig. 3). The $B S_{45^{\circ}}$ versus frequency exhibits different patterns for the four test sites. The measurements from the Renard site show high values for all frequencies; the variation with frequency is more pronounced at frequencies below $100 \mathrm{kHz}$ and becomes negligible for frequencies greater than $300 \mathrm{kHz}$ (around $-13 \mathrm{~dB}$ ). For the Rascass and Aulne sites, the $B S_{45^{\circ}}$ values are very similar (inside their common frequency interval from 90 to $450 \mathrm{kHz}$ ) and are lower than the values observed on Renard; for both areas, the mean oblique BS strength increases continuously with the increasing frequency. For both Renard and Rascass sites, the $B S_{45^{\circ}}$ values increase at a higher rate in the frequency interval from 45 to $100 \mathrm{kHz}$. Data from Elorn show lower $B S_{45^{\circ}}$ levels $(-25$ to $-21 \mathrm{~dB}$ ) that increase regularly with frequency.

The frequency dependence of the BS strength is often modelled by a frequency power exponent (Cutter and Demer, 2014; Weber and Ward, 2015; Wendelboe, 2018; Williams et al., 2009), expressed as

$$
B S(\theta, f)=B S(\theta) f^{C_{f}},
$$

where $f$ is the frequency $(\mathrm{Hz})$ and $C_{f}$ is its power exponent; we assume here that $C_{f}$ is prone to vary with the incidence angle.

The frequency power parameters are estimated in the logarithmic domain, using the linear least-square method. Figure 10 presents the estimated frequency dependence of the mean oblique BS strength $B S_{45^{\circ}}$ with frequency over the complete frequency range, a fact that was observed for the four sediment types studied here. The residual differences between the observed and predicted $B S(f)$ values (based on the power exponent adjusted for each of the four areas) do not exceed $\pm 1 \mathrm{~dB}$, with the notable exception of the lowest frequencies 35 and $45 \mathrm{kHz}$ (also omitting the $280 \mathrm{kHz}$ values due to the instability observable in the calibration process at this particular frequency; see Fig. 3). The data within the Renard site suggest a steeper frequency dependence at frequencies below $90 \mathrm{kHz}$, possibly a consequence of a physically different BS regime. These observations are still unconclusive due to the limitations of the available dataset presented here, and this trend will have to be verified by new measurements on other sites in this frequency range. The lowest frequency power exponent $\left(C_{f}=0.56\right)$ was 

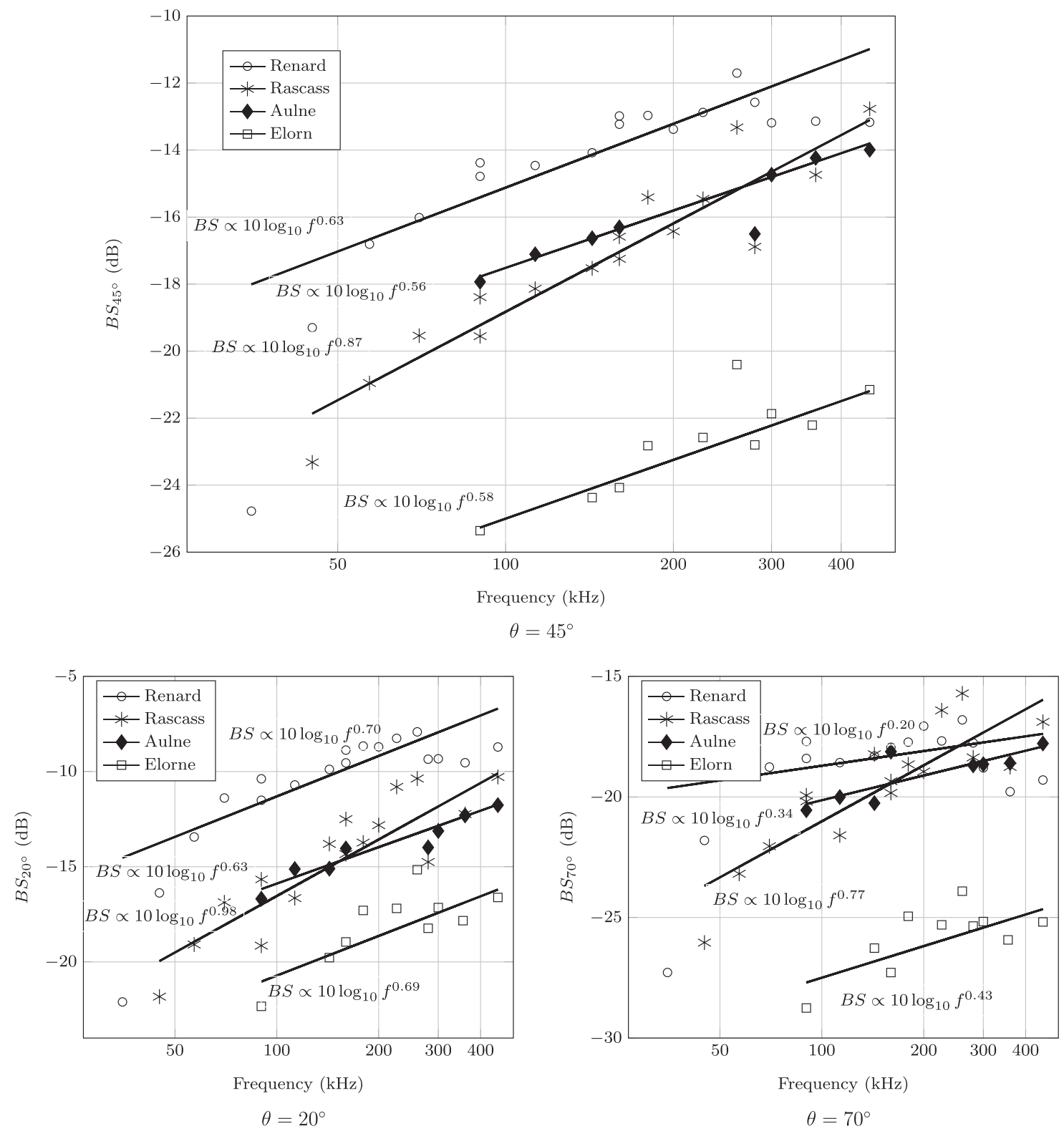

FIG. 10. Bottom BS strength versus frequency measured at three incidence angles $\left(45^{\circ}-20^{\circ}-70^{\circ}\right)$ at the four sites. Best-fit lines are superimposed on the data.

observed at the Aulne site, and the highest one $\left(C_{f}=0.87\right)$ was observed at the Rascass site. The data acquired on Aulne and Elorn suggest very similar increases of the mean BS strength with increasing frequency, which are consistent with $B S \propto 10 \log _{10} f^{0.56}$ and $B S \propto 10 \log _{10} f^{0.58}$, respectively. The intersection between the best-fit lines at Aulne and Rascass sites occurs around $270 \mathrm{kHz}$, illustrating that the mean oblique BS strength at this frequency is equal for both sites, although they are covered by different sediment types; this result illustrates the potential interest of multispectral seafloor characterization to combat such ambiguities.

The general trends observed for $B S_{45^{\circ}}$ in the frequency range from 35 to $450 \mathrm{kHz}$ on the four study sites suggest a frequency dependence slightly varying with the sediment type. The exponent values for the various sites (including coarse sand and gravel, gravelly mud with shells, silty sand with shells, and mud) show only little variation, from $C_{f}=0.56$ to $C_{f}=0.87$. These values are consistent with most historical data (see Table I), giving an overall frequency dependence of the Lambert's parameter varying from $C_{f}=0.0$ to $C_{f}=2.0(0-6 \mathrm{~dB} /$ octave $)$. However, this agreement is of limited significance, since the historical data correspond to a wide variety of experimental conditions, systems, and methods. The frequency dependence for our four experimental sites is presented in Fig. 10 for two other incidence angles $\left(20^{\circ}\right.$ and $\left.70^{\circ}\right)$. The overall trends for all four sites suggest a general decrease in the frequency dependence slope with increasing incidence angle. For all sites, regardless of the incidence angle, the BS estimates vary from 0.6 to $3 \mathrm{~dB} /$ octave, which is equivalent to a $C_{f}$ variation from 0.2 (Renard at $70^{\circ}$ ) to 0.98 (Rascass at $20^{\circ}$ ). The frequency dependence at $20^{\circ}$ is similar to that observed at $45^{\circ}$, 
with a small increasing shift (about 0.1 ) of the frequency exponent. On the other hand, the frequency exponent decreases for all sites at $70^{\circ}$ when compared to $45^{\circ}$. The smallest values were obtained for Renard and Aulne sites with $C_{f}=0.2$ and $C_{f}=0.34$, respectively. This trend, calculated for the four visited sites, is consistent with the one observed for the $B S_{N}-B S_{O}$ difference.

Interestingly, Cutter and Demer (2014) presented data obtained from seven areas with different sediment types, including sand, gravel, and rock, at incident angles spanning $2^{\circ}-20^{\circ}$. Comparably to the results presented here, their data were acquired with a multifrequency SBES (Simrad EK60) with nominal frequencies $f=18,38,70,120$, and $200 \mathrm{kHz}$, showing a fluctuating frequency dependence from -0.7 to $3.1 \mathrm{~dB} /$ octave. In the present paper, the estimated frequency dependence for $\theta=20^{\circ}$ varies from 1.9 to $3 \mathrm{~dB} /$ octave for all frequencies and for all sites. Comparisons between the two studies are complex, as they were conducted over different sediment types. Nevertheless, in our case, the frequency dependence at $\theta=20^{\circ}$ incidence angle appears to be more stable, probably due to a better determination of the incident angles and insonified areas, which are calculated based on a tilted beam over an accurately known flat seabed, instead of a vertical beam over changing seafloor slopes (Cutter and Demer, 2014).

Also, similarly, Weber and Ward (2015) measured the scattering strength from sand and gravel seafloor at incidence angles near $45^{\circ}$, using a calibrated SBES. They found a decreasing trend of BS strength values with frequency over a relatively narrow spectral range $(170-250 \mathrm{kHz})$. This negative frequency dependence was not observed in the results presented here, which consistently showed BS values increasing with frequency. The spectral slopes found by Wendelboe (2018) for a sandy seafloor are similar to the ones estimated here at $\theta=20^{\circ}$ and $\theta=45^{\circ}$; however, a change to a steeper frequency dependence rate was found for frequencies above $350 \mathrm{kHz}$, which is not observed in our results. Finally, at shallower grazing angles, the values found here for the frequency dependence coefficient are very similar to those from historical studies summarized in Table I.

\section{CONCLUSION}

The present study has presented experimental results of seafloor BS using a calibrated tilted echosounder with a total frequency bandwidth exceeding three octaves and an angular extent of $70^{\circ}$. These results illustrate the discriminating potential of multispectral wide-angle measurements. The angular dependence at a given frequency can be readily and accurately fitted by the GSAB model. The frequency exponent values obtained from BS measurements appear to differ significantly, depending on the seafloor material and the angle of incidence. The frequency dependence observed at oblique angle $45^{\circ}$ is intermediate between the frequency dependences observed at steep $\left(\theta=20^{\circ}\right)$ and grazing angles $\left(\theta=70^{\circ}\right)$. The results of the multispectral analysis suggest that the frequencies around and below $100 \mathrm{kHz}$ tend to provide a better potential for discrimination. In the cases of Renard and Rascass sites, the BS strength values measured at low frequencies (from 35 to $90 \mathrm{kHz}$ ) show stronger variations than the values measured at higher frequencies (above $100 \mathrm{kHz}$ ); this observation needs further confirmation from additional measurements on different seafloor areas at low frequencies. The frequency dependence magnitudes observed on the four sites studied here are compatible with those reported in previous work at different incidence angles. The statistical analysis of BS amplitudes shows a variation of the distribution shape in the near-nadir angle sector that depends both on the sediment type and on the number of BS samples. From an operational point of view, the use of a tilted calibrated wideband SBES proved to be a practical solution for recording absolute values of $\mathrm{BS}$ strength at different frequencies and incident angles. The soobtained calibrated ARs are expected to be of interest for remote seabed property characterization (Fezzani and Berger, 2018; Jackson et al., 1986a; Lamarche et al., 2011), for geoacoustic model parameter estimation (Fonseca and Mayer, 2007; Jackson et al., 1986b), and for crosscalibration of multibeam echosounders (Eleftherakis et al., 2018).

\section{ACKNOWLEDGMENT}

This work was conducted in the framework of IFREMER R\&D Project R403-006 (Underwater Acoustics). We would like to thank the Kongsberg Maritime Company for making available a special version of their code allowing the use of EK80 at different frequencies with $\mathrm{CW}$ mode and for lending us a WBT Mini system. We would like to express our gratitude to the RV Thalia crew for their involvement during the measurement days at sea.

Amiri-Simkooei, A., Snellen, M., and Simons, D. G. (2009). "Riverbed sediment classification using multi-beam echo-sounder backscatter data," J. Acoust. Soc. Am. 126(4), 1724-1738.

Brekhovskikh, L. M., Lysanov, Y. P., and Beyer, R. T. (1991). Fundamentals of Ocean Acoustics, 2nd ed. (Springer-Verlag, Berlin).

Brown, C. J., Beaudoin, J., Brissette, M., and Gazzola, V. (2019). "Multispectral multibeam echo sounder backscatter as a tool for improved seafloor characterization," Geosciences 9(3), 126.

Clarke, J. H. (2015). "Multispectral acoustic backscatter from multibeam, improved classification potential," in Proceedings of the United States Hydrographic Conference, March 16-19, National Harbor, MD, pp. 15-19.

Cutter, G. R., and Demer, D. A. (2014). "Seabed classification using surface backscattering strength versus acoustic frequency and incidence angle measured with vertical, split-beam echosounders," ICES J. Mar. Sci. 71(4), 882-894.

Demer, D. A., Andersen, L. N., Bassett, C., Berger, L., Chu, D., Condiotty, J., and Cutter, G. R. (2017). "Evaluation of a wideband echosounder for fisheries and marine ecosystem science," ICES Cooperative Research Report No. 336 (International Council for the Exploration of the Sea, Copenhagen, Denmark).

Demer, D. A., Berger, L., Bernasconi, M., Bethke, E., Boswell, K., Chu, D., Domokos, R., Dunford, A., Fassler, S., Gauthier, S., Hufnagle, L. T., Jech, J. M., Bouffant, N., Lebourges-Dhaussy, A., Lurton, X., Macaulay, G. J., Perrot, Y., Ryan, T., Parker-Stetter, S., Stienessen, S., Weber, T., and Williamson, N. (2015). "Calibration of acoustic instruments," ICES 
Cooperative Research Report No. 326 (International Council for the Exploration of the Sea, Copenhagen, Denmark).

Eleftherakis, D., Berger, L., Le Bouffant, N., Pacault, A., Augustin, J.-M., and Lurton, X. (2018). "Backscatter calibration of high-frequency multibeam echosounder using a reference single-beam system, on natural seafloor," Mar. Geophys. Res. 39(1), 55-73.

Feldens, P., Schulze, I., Papenmeier, S., Schönke, M., and Schneider von Deimling, J. (2018). "Improved interpretation of marine sedimentary environments using multi-frequency multibeam backscatter data," Geosciences 8(6), 214.

Fezzani, R., and Berger, L. (2018). "Analysis of calibrated seafloor backscatter for habitat classification methodology and case study of 158 spots in the bay of biscay and celtic sea," Mar. Geophys. Res. 39(1), 169-181.

Fonseca, L., Lurton, X., Fezzani, R., Augustin, J.-M., and Berger, L. (2021). "A statistical approach for analyzing and modeling multibeam echosounder backscatter, including the influence of high-amplitude scatterers," J. Acoust. Soc. Am. 149(1), 215-228.

Fonseca, L., and Mayer, L. (2007). "Remote estimation of surficial seafloor properties through the application angular range analysis to multibeam sonar data," Mar. Geophys. Res. 28(2), 119-126.

Gaida, T., Ali, T. T., Snellen, M., Amiri-Simkooei, A., van Dijk, T., and Simons, D. (2018). "A multispectral Bayesian classification method for increased acoustic discrimination of seabed sediments using multifrequency multibeam backscatter data," Geosciences 8(12), 455.

Greenlaw, C. F., Holliday, D. V., and McGehee, D. E. (2004). "High frequency scattering from saturated sand sediments," J. Acoust. Soc. Am. 115(6), 2818-2823.

Gregoire, G., Ehrhold, A., Le Roy, P., Jouet, G., and Garlan, T. (2016). "Modern morpho-sedimentological patterns in a tide-dominated estuary system: The Bay of Brest (West Britanny, France)," J. Maps 12(5), 1152-1159.

Jackson, D., and Richardson, M. (2007). High-Frequency Seafloor Acoustics (Springer Science and Business Media, New York).

Jackson, D. R., Baird, A. M., Crisp, J. J., and Thomson, P. A. G. (1986a). "High frequency bottom backscatter measurements in shallow water," J. Acoust. Soc. Am. 80(4), 1188-1199.

Jackson, D. R., Winebrenner, D. P., and Ishimaru, A. (1986b). “Application of the composite roughness model to high-frequency bottom backscattering," J. Acoust. Soc. Am. 79(5), 1410-1422.

Janowski, L., Trzcinska, K., Tegowski, J., Kruss, A., Rucinska-Zjadacz, M., and Pocwiardowski, P. (2018). "Nearshore benthic habitat mapping based on multi-frequency, multibeam echosounder data using a combined object-based approach: A case study from the Rowy site in the southern Baltic Sea," Remote Sens. 10(12), 1983.

Lamarche, G., Lurton, X., Verdier, A.-L., and Augustin, J.-M. (2011). "Quantitative characterisation of seafloor substrate and bedforms using advanced processing of multibeam backscatter-application to Cook Strait, New Zealand," Continental Shelf Res. 31(2), S93-S109.

Le Chenadec, G., Boucher, J.-M., and Lurton, X. (2007). "Angular dependence of K-distributed sonar data," IEEE Trans. Geosci. Remote Sens. 45(5), 1224-1235.

Lurton, X., and Lamarche, G. (2015). "Backscatter measurements by seafloor-mapping sonars: Guidelines and recommendations," https:// niwa.co.nz/static/BWSG_REPORT_MAY2015_web.pdf (Last viewed $15 / 06 / 2021)$

Lyons, A. P., and Abraham, D. A. (1999). "Statistical characterization of high-frequency shallow-water seafloor backscatter," J. Acoust. Soc. Am. 106(3), 1307-1315.

McKinney, C. M., and Anderson, C. D. (1964). "Measurements of backscattering of sound from the ocean bottom," J. Acoust. Soc. Am. 36(1), $158-163$.

Penrose, J. D., Gavrilov, A., and Parnum, I. M. (2008). "Statistics of seafloor backscatter measured with multibeam sonar systems," J. Acoust. Soc. Am. 123(5), 3628-3628.

Roche, M., Degrendele, K., Vrignaud, C., Loyer, S., Le Bas, T., Augustin, J.-M., and Lurton, X. (2018). "Control of the repeatability of high frequency multibeam echosounder backscatter by using natural reference areas," Mar. Geophys. Res. 39(1), 89-104.

Stanic, S., Briggs, K. B., Fleischer, P., Sawyer, W. B., and Ray, R. I. (1989). "High frequency acoustic backscattering from a coarse shell ocean bottom," J. Acoust. Soc. Am. 85(1), 125-136.

Urick, R. J. (1954). "The backscattering of sound from a harbor bottom," J. Acoust. Soc. Am. 26(2), 231-235.

Weber, T. C., and Ward, L. G. (2015). "Observations of backscatter from sand and gravel seafloors between 170 and $250 \mathrm{kHz}$," J. Acoust. Soc. Am. 138(4), 2169-2180.

Wendelboe, G. (2018). "Backscattering from a sandy seabed measured by a calibrated multibeam echosounder in the 190-400 khz frequency range," Mar. Geophys. Res. 39(1), 105-120.

Williams, K. L., Jackson, D., Tang, R. D., Briggs, K. B., and Thorsos, E. I. (2009). "Acoustic backscattering from a sand and a sand/mud environment: Experiments and data/model comparisons," IEEE J. Ocean. Eng. 34(4), 388-398. 